\title{
A Novel Fluorescent Probe for Selective Detection of Hydrazine and Its Application in Imaging
}

\author{
Ruo-Jun Man ${ }^{1, *,{ }^{\dagger}}$, Meng-Ke Wu ${ }^{1, \dagger}$, Bing Yang ${ }^{2, *}$ and Yu-Shun Yang ${ }^{3, *}$ \\ 1 Guangxi Biological Polysaccharide Separation, Purification and Modification Research Platform, \\ Guangxi University for Nationalities, Nanning 530006, China; wmk135076@163.com \\ 2 School of Chemistry and Chemical Engineering, Nantong University, Nantong 226019, China \\ 3 Research Centre of Sensors and Functional Materials, Hi-Techjig Co. Ltd., Zhenjiang 212415, China \\ * Correspondence: manruojun@163.com (R.-J.M.); yangbing111@ntu.edu.cn (B.Y.); \\ ys_yang@nju.edu.cn (Y.-S.Y.); Tel.: +86-258-968-2572 (Y.-S.Y.) \\ + The authors contributed equally to this work.
}

check for

updates

Citation: Man, R.-J.; Wu, M.-K.; Yang, B.; Yang, Y.-S. A Novel Fluorescent Probe for Selective Detection of Hydrazine and Its Application in Imaging. Biosensors 2021, 11, 130. https://doi.org/ $10.3390 /$ bios 11050130

Received: 23 March 2021

Accepted: 18 April 2021

Published: 22 April 2021

Publisher's Note: MDPI stays neutral with regard to jurisdictional claims in published maps and institutional affiliations.

Copyright: (c) 2021 by the authors. Licensee MDPI, Basel, Switzerland. This article is an open access article distributed under the terms and conditions of the Creative Commons Attribution (CC BY) license (https:/ / creativecommons.org/licenses/by/ $4.0 /)$.

\begin{abstract}
In this work, a novel fluorescent probe with first-time-selected thiazepine backbone, TZPzine-1, was developed for selective detection of hydrazine in water samples and living cells. Chosen from our recent anti-cancer agents, TZPzine-1 inferred structurally based advantages of the optical adjustability and the hydrazine-trapping approach. It also showed applicable properties including high sensitivity (LOD = $50 \mathrm{nM}$ ), wide linear range (0-15 equiv.), high selectivity (especially from competing species), rapid response (within $20 \mathrm{~min}$ ), and practical steadiness in various $\mathrm{pH}$ (6.0-11.0) and temperature $\left(15-50^{\circ} \mathrm{C}\right)$ conditions. To satisfy the interdisciplinary requirements in environmental toxicology, TZPzine-1 was successfully applied in water samples and living cells. We hope that the information in this work, as well as the concept of monitoring the nitrogen cycle, may be referable for future research on systematic management.
\end{abstract}

Keywords: hydrazine detection; fluorescent probe; biological imaging; thiazepine moiety; water samples

\section{Introduction}

Nitrogen-based compounds, as components of the nitrogen cycle, travel all through the manufacturing industry, the environment, plants, animals, and humans [1]. Among them, due to its reductivity and basicity, hydrazine $\left(\mathrm{NH}_{2} \mathrm{NH}_{2}\right)$ seems to be one of the most important species in industrial and medicinal applications [2,3]. This highly toxic hydrazine is common in wastewater from dyeing, synthetic, or zymotic factories $[4,5]$. Accordingly, its minimum limit of potential carcinogen was determined as $10 \mathrm{ppb}$ by the US Environmental Protection Agency (EPA) [6]. Therefore, it is of significant value to monitor the level of hydrazine with novel methods.

Previous approaches for the detection of hydrazine include electrochemistry [7], Raman spectroscopy [8], colorimetry [9], chemiluminescence [10], spectrophotometry [11], and titrimetry [12]. To avoid a complex preparation and strict procedures, researchers who are interested in convenient detection have paid attention to fluorescent probes [13]. As reported, a typical probe includes the fluorophore (such as benzothiazole [14], 1,8-naphthalene imide [15], coumarin [16], rhodamine [17], phenothiazine [18], carbazole [19], and cyanine dye [20]) and the recognition group (such as acetyl [21], levulinate [22], 4-bromo butyrate [23], phthalimide [24], aldehyde [25], cyano [26]). As we claimed in our previous work [27], compared with complex tools (such as rare earth [28], aggregation-induced enhancement (AIE) [29], nanoparticles [30], or carbon dots [31]), small molecular probes were preferred in the closed-loop monitoring of hydrazine circulation. Thus, novel mechanisms for recognizing hydrazine with specific cases are still urgently needed.

In this work, we introduced a novel structure which was obtained in our investigation of anti-cancer agents [32] for the detection of hydrazine in water samples and living cells. 
As shown in Figure 1, this thiazepine-containing probe, TZPzine-1 ("TZP" for thiazepine and "zine" for hydrazine), was transformed into pyrazole derivative by hydrazine under aerobic environment. Since the optimization of the substitutes and the oxidizing conditions might be another methodological story, here we focused on the detecting capability, with TZPzine- 1 as an example. Structurally, we could conclude that TZPzine- 1 had two potential advantages. One was that the optical properties could be regulated by changing the substitutes, while the other was that hydrazine was trapped in the fluorophore after the detection, unlike the departure in common mechanisms [21-24]. As compared with the previous reports in Table S1 in Supporting Information (SI), TZPzine-1 showed a fast response within $20 \mathrm{~min}$ and a high selectivity. The limit of detection (LOD) was calculated as $50 \mathrm{nM}$, fulfilling the EPA standard. We then performed the application of TZPzine- 1 in water samples and living cells.

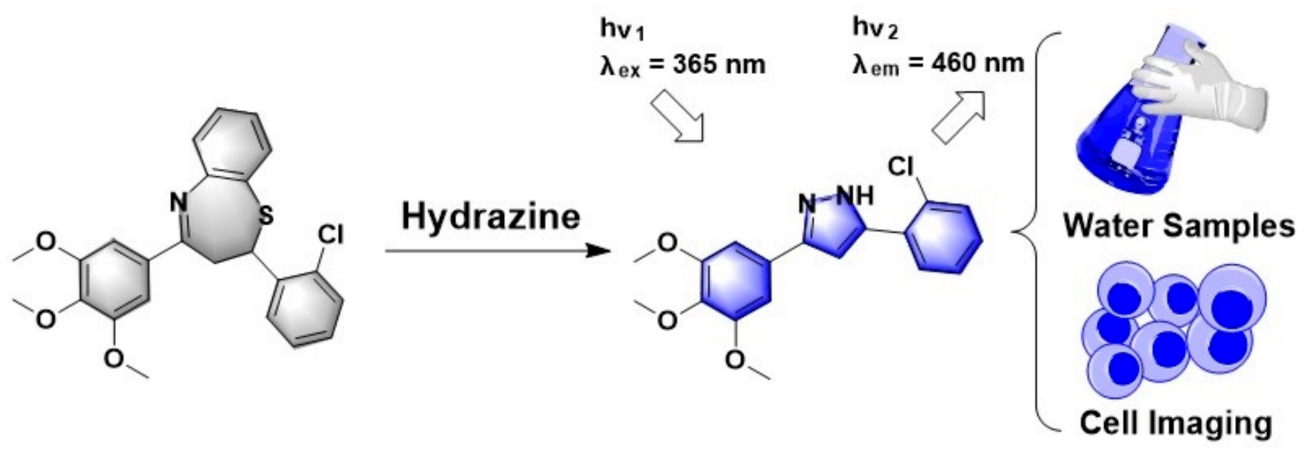

Figure 1. Illustration of the TZPzine-1 for the detection of hydrazine.

\section{Experimental}

\subsection{Materials and Methods}

The purchased chemicals were used directly without further purification. ${ }^{1} \mathrm{H}$ NMR and ${ }^{13} \mathrm{C}$ NMR spectra were recorded on a Bruker DRX-600 spectrometer (Karlsruhe, Germany), and the data were analyzed with MestreNova software (Santiago de Compostela, Spain). Mass spectra were recorded on Agilent 6540 UHD Accurate Mass Q-TOF LC/MS (Santa Clara, CA, USA). The UV-vis test was conducted on a Shimadzu UV-2550 spectrometer (Kyoto, Japan). All the fluorescence tests were performed on a Hitachi F-7000 Fluorescence Spectrometer (Tokyo, Japan). The imaging was conducted on a Leica TCS SP8 MP two-photon confocal fluorescent microscope (Weztlar, Germany).

The stocking solution of the probe TZPzine- 1 was prepared in DMSO at the concentration of $1.0 \mathrm{mM}$. Other concentrations were obtained by dilution. In the selectivity experiments, the concentration of hydrazine was set as $300 \mu \mathrm{M}$, while that of the other analytes was set as $1.0 \mathrm{mM}$. The excitation wavelength was set at $365 \mathrm{~nm}$. Both excitation and emission slit widths were $10 \mathrm{~nm}$. The photomultiplier voltage was $600 \mathrm{~V}$.

\subsection{Water Sample Pretreatment}

Water samples were collected from Guangxi University for Nationalities, Nanning (rainwater, tap water, and rice water), Zhenjiang Gexian Lake (lake water), Yangtze River Zhenjiang Section (river water), and the East China Sea near Nantong, Jiangsu Province, China (sea water). The samples were all coded and transported to our laboratory. Subsequently, the water samples were placed statically overnight and filtered. The $\mathrm{pH}$ values of the samples were tested to ensure that they were all between 7.0 and 8.0. The pretreated water samples were used as the solution system in the tests, instead of PBS, without further dilution.

\subsection{Synthesis of the Probe TZPzine-1}

The synthesis of the probe TZPzine- 1 was illustrated in Figure 2. According to our previous report [32], 1-(3,4,5-trimethoxyphenyl) ethan-1-one (1 mmol, $0.210 \mathrm{~g})$ was added 
to a $5 \mathrm{~mL}$ ethanol solution of 2-chlorobenzaldehyde ( $1 \mathrm{mmol}, 0.140 \mathrm{~g})$. Then, $50 \% \mathrm{NaOH}$ $(0.5 \mathrm{~mL})$ was added to the mixture dropwise. The completion of the reaction was checked by thin layer chromatography. Afterwards, the mixture was filtered, washed by cold ethanol, and dried, to acquire the intermediate B (0.293 g, yielding 88.3\%). Subsequently, intermediate B $(0.5 \mathrm{mmol}, 0.166 \mathrm{~g})$ was dissolved in ethanol under reflux condition. To the hot solution, 2-aminothiophenol ( $0.5 \mathrm{mmol}, 0.063 \mathrm{~g})$ was added, and then concentrated hydrochloric acid was added dropwise. The reaction was kept running continuously for $4 \mathrm{~h}$. The crude product was filtered, washed with cold ethanol, dried, and recrystallized to obtain the probe TZPzine-1 (0.141 g, yielding 64.2\%). The grey-white powder melt point is $139-140{ }^{\circ} \mathrm{C} .{ }^{1} \mathrm{H}$ NMR $\left(600 \mathrm{MHz}, \mathrm{DMSO}-d_{6}\right) \delta 7.65(\mathrm{~d}, J=7.68 \mathrm{~Hz}, 1 \mathrm{H}, \mathrm{ArH}), 7.63(\mathrm{~d}$, $J=7.68 \mathrm{~Hz}, 1 \mathrm{H}, \mathrm{ArH}), 7.55(\mathrm{t}, J=7.7 \mathrm{~Hz}, 1 \mathrm{H}, \mathrm{ArH}), 7.50(\mathrm{~d}, J=7.7 \mathrm{~Hz}, 1 \mathrm{H}, \mathrm{ArH}), 7.46$ (s, 2H, ArH), 7.38-7.32 (m, 2H, ArH), $7.30(\mathrm{~d}, J=7.9 \mathrm{~Hz}, 1 \mathrm{H}, \mathrm{ArH}), 7.21(\mathrm{t}, J=7.6 \mathrm{~Hz}, 1 \mathrm{H}$, $\mathrm{ArH}), 5.48\left(\mathrm{dd}, J=13.0,4.6 \mathrm{~Hz}, 1 \mathrm{H},-\mathrm{CH}_{2}-\right), 3.88\left(\mathrm{~s}, 6 \mathrm{H},\left(-\mathrm{OCH}_{3}\right)_{2}\right), 3.77(\mathrm{~s}, 3 \mathrm{H},-\mathrm{OCH} 3)$, $3.55\left(\mathrm{dd}, J=13.1,4.6 \mathrm{~Hz}, 1 \mathrm{H},-\mathrm{CH}_{2}-\right), 2.77(\mathrm{t}, J=13.1 \mathrm{~Hz}, 1 \mathrm{H},-\mathrm{S}-\mathrm{CH}-) .{ }^{13} \mathrm{C} \mathrm{NMR}(151 \mathrm{MHz}$, DMSO-d $\left.d_{6}\right) \delta 168.28,153.46,152.67,141.27,140.90,135.39,132.58,130.99,130.70,129.87$, $129.77,128.36,128.15,125.89,125.65,122.05,105.24,60.65,60.23,56.47$. HRMS (ESI-TOF) $\mathrm{m} / \mathrm{z}:[\mathrm{M}+\mathrm{H}]^{+}$Calcd. for $\mathrm{C}_{24} \mathrm{H}_{23} \mathrm{ClNO}_{3} \mathrm{~S} 440.1087$, Found 440.1082.

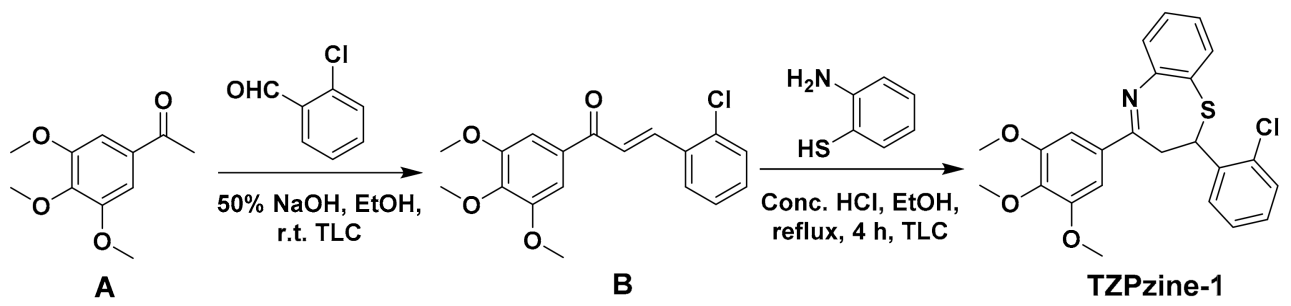

Figure 2. General synthesis route of the probe TZPzine-1.

\section{Results and Discussion}

\subsection{Synthesis of the Probe TZPzine-1}

The probe TZPzine-1 was synthesized according to the general route in Figure 2, as mentioned in our previous report in medicinal chemistry [32]. The structure was confirmed by satisfactory spectroscopic data $\left({ }^{1} \mathrm{H}\right.$ NMR, ${ }^{13} \mathrm{C}$ NMR and HRMS, Figures S6-S9, SI). In this work, we only took TZPzine-1 as a representative, and the optical capability could actually be regulated by changing the substitutes.

\subsection{Fluorescent Properties for Detecting Hydrazine}

Under the excitation wavelength of $365 \mathrm{~nm}$, the fluorescence spectra of the probe TZPzine- 1 and the detecting system suggested that the weak emission peak of TZPzine-1 at $515 \mathrm{~nm}$ and the strong emission peak at $460 \mathrm{~nm}$ appeared after the addition of hydrazine. The response to hydrazine caused an over 30-fold enhancement in fluorescence intensity at $460 \mathrm{~nm}$, and a Stokes shift of $95 \mathrm{~nm}$. The fluorescence intensity came to the plateau when the concentration of the added hydrazine reached 30 equivalent (equiv. or Eq). Therefore, the sensing system consisting of TZPzine-1 $(10 \mu \mathrm{M})$ and hydrazine $(300 \mu \mathrm{M})$, in a PBS buffer (pH 7.4, $10 \mathrm{mM}, 1 \%$ DMSO $v / v$ ), at $37{ }^{\circ} \mathrm{C}$ was used to check responses to different external conditions. Accordingly, the fluorescence signal of TZPzine-1 remained steady within the $\mathrm{pH}$ range of 6.0-12.0 while the detecting system was stable within 5.0-11.0, which inferred the wide window of 6.0-11.0 for practical use (Figure S1, SI). The test, under various temperature conditions, suggested that the probe and the detecting system were both steady in the range of $15-50{ }^{\circ} \mathrm{C}$ (Figure S2, SI), which was beneficial for the consistency between the environmental (usually $25^{\circ} \mathrm{C}$ ) and biological (usually $37{ }^{\circ} \mathrm{C}$ ) samples. Moreover, the detecting procedure could be completed within 20 min, which was relatively rapid, whereas the response period could be extended to over 60 min when we used a nitrogen-filled balloon to set a simple hypoxic condition (Figure S3, SI). This 
might be an interesting point in the research of water eutrophication, but is not the focus of this work.

As shown in Figure 3, an obvious turn-on variation in the fluorescence at $460 \mathrm{~nm}$ could be observed from the fluorescent spectrum of TZPzine-1 (10 $\mu \mathrm{M})$, with increasing concentration of hydrazine $(0-500 \mu \mathrm{M})$. As we mentioned, the plateau was reached with 30 equiv. hydrazine. Accordingly, the linear range was $0-15$ equiv. $(0-150 \mu \mathrm{M})$. The limit of detection (LOD) was calculated as $50 \mathrm{nM}$ (0.005 equiv.) from the formula $3.29 \sigma / \mathrm{k}$ ( $\sigma$ meant the deviation of 25 tests in the detecting system with no hydrazine; $\mathrm{k}$ meant the slope of the linear fitting). The limit of quantity (LOQ) was tested to be $100 \mathrm{nM}$ (0.010 equiv.) by continuously diluting the concentration of hydrazine. The wide linear range and the high sensitivity guaranteed the capability of TZPzine-1 in practical applications.
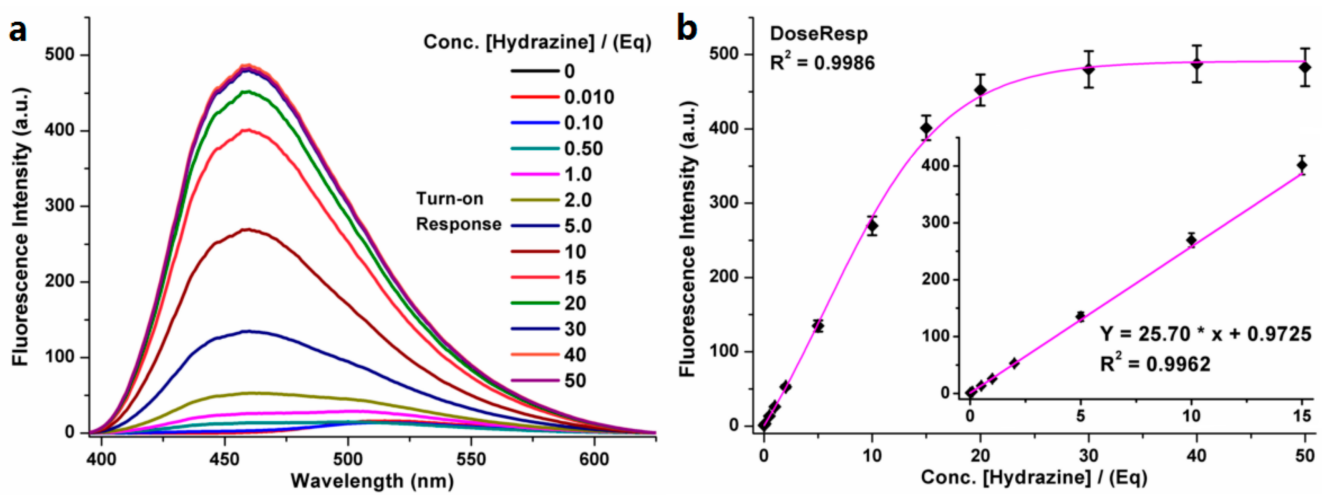

Figure 3. (a) The fluorescence spectra of TZPzine-1 $(10 \mu \mathrm{M})$ in PBS buffer (10 mM, pH 7.4, $1 \%$ DMSO $v / v)$ after treatment with hydrazine $(0-500 \mu \mathrm{M})$ for $20 \mathrm{~min}$; (b) The curve between the fluorescence intensity and the concentration of hydrazine $(0-500 \mu \mathrm{M})$; b-Inner: The linear relationship between the fluorescence intensity and the concentration of hydrazine $(0-150 \mu \mathrm{M})$.

\subsection{Selectivity for Hydrazine}

Subsequently, based on the intensity ratios $\left(\mathrm{F} / \mathrm{F}_{0}, \mathrm{~F}\right.$ : Intensity of response; $\mathrm{F}_{0}$ : Intensity of control) at $460 \mathrm{~nm}$, the selectivity of TZPzine- 1 for hydrazine was checked from various analytes (Figure $4 a, b$ ). As shown, except for hydrazine, none of the analytes could cause an obvious increase in the fluorescent signal. In particular, the competing species acetohydrazide and phenylhydrazine could be easily distinguished from hydrazine. This might be quite important in the detection of hydrazine. Meanwhile, in the coexistence system with both hydrazine and other analytes, the detection of hydrazine was not interfered (Figure 4c,d). Accordingly, the selectivity of TZPzine-1 for hydrazine was steady in both situations of independence and coexistence, which further ensured the potential of this probe.

\subsection{The Reaction Mechanism}

The reaction mechanism between TZPzine-1 and hydrazine, as illustrated in Figure 5, was different from typical ones. Since the theoretical mechanism involved a slight oxidation after the cyclization, it was quite difficult to separate the product from the detecting system due to the stickiness. Still, we were able to check the HRMS spectrum of the pyrazole product (Figure S9, SI) with the help of the reports on similar backbones $[33,34]$. In this mechanism, hydrazine was trapped in the fluorophore after the detection, unlike the departure in common ones. Moreover, this mechanism agreed with the selectivity of TZPzine-1 for hydrazine from competing species such as acetohydrazide and phenylhydrazine according to the factors, including electronic status, steric hindrance, and product stability. The Job's plot analysis for TZPzine-1 and hydrazine interaction (Figure S4, SI) confirmed the 1:1 ratio of binding pattern, which agreed with the trapping one. Since the probe in this work chose a trapping mechanism, although the highly toxic hydrazine was better treated (trapped into the detecting product), the detected product could not be 
easily transformed into the synthetic precursor of the probe. Accordingly, the downstream use of the detecting product was realized by including it as the intermediate in medicinal chemistry $[33,34]$. Actually, the detection of hydrazine required less raw materials than the medicinal development. Therefore, although a bit different from the typical reversibility of previous probes $[35,36]$, the recycling of the probe in this work was achieved within a systemic circulation of several industrial chains.
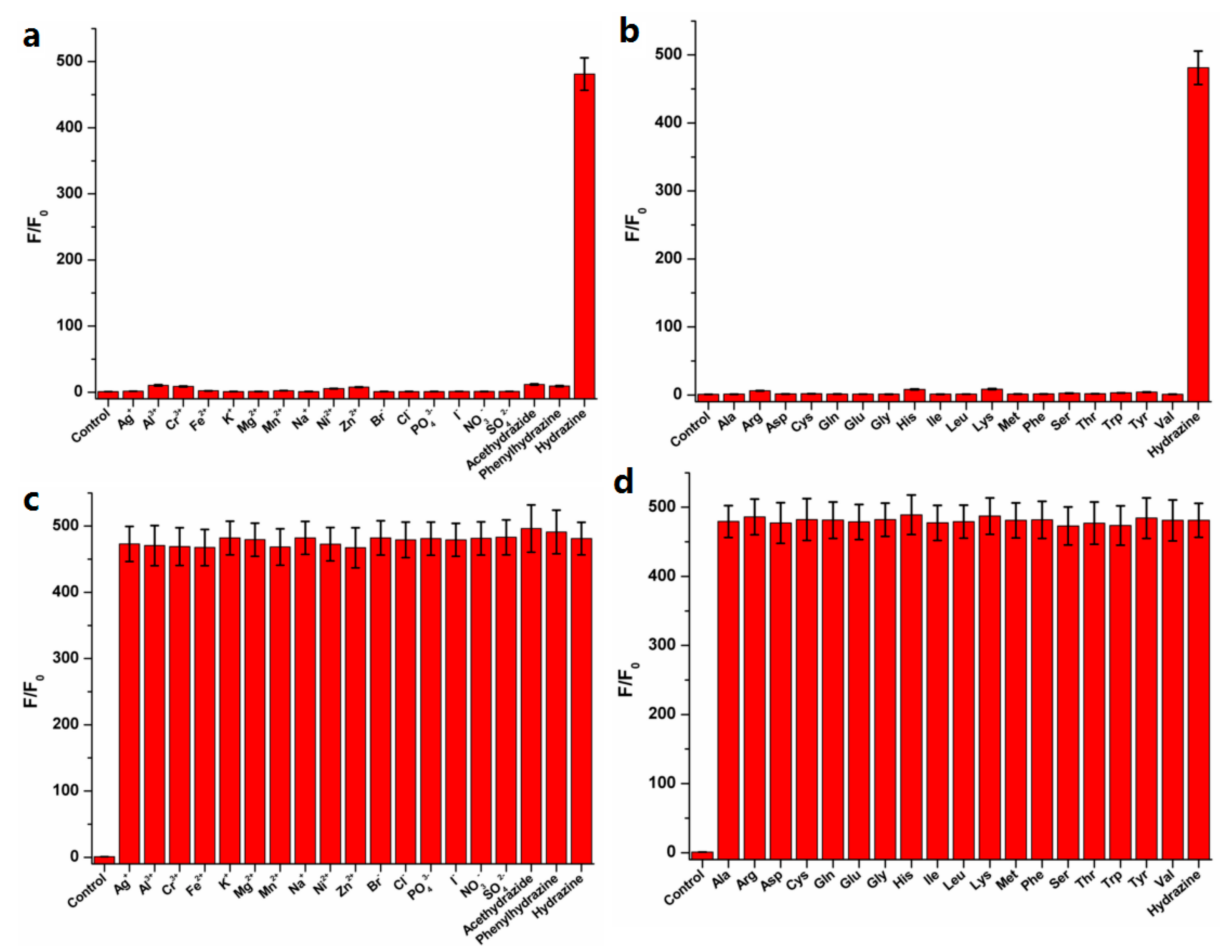

Figure 4. The intensity ratios $\left(\mathrm{F} / \mathrm{F}_{0}\right)$ at $460 \mathrm{~nm}$ in $\mathrm{PBS}$ buffer $(10 \mathrm{mM}, \mathrm{pH} 7.4,1 \% \mathrm{DMSO} v / v)$ at $37^{\circ} \mathrm{C}$ indicated the selectivity of TZPzine- 1 towards hydrazine from (a) ions or competing species, (b) amino acids, as well as in the coexistence systems containing (c) ions or competing species, (d) amino acids.

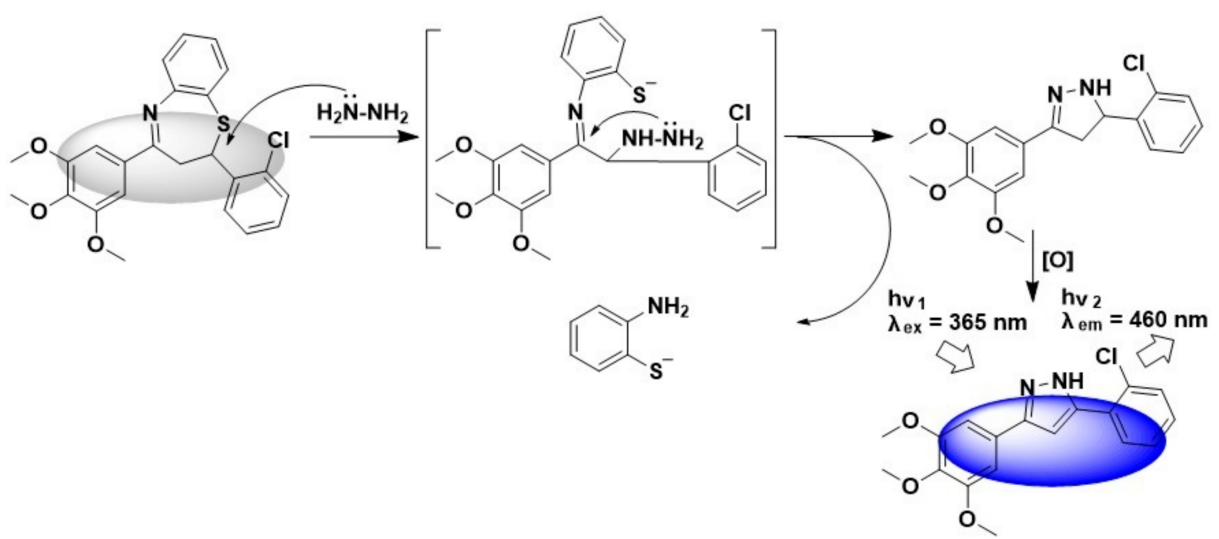

Figure 5. The illustrated reaction mechanism between TZPzine-1 and hydrazine.

\subsection{Application in Water Samples}

Since hydrazine is a toxic pollutant mainly found in wastewater, we used water samples from different sources to check the performance of TPZzine-1. The water samples were collected in the cities of Nanning, Zhenjiang, and Nantong in China. They covered the sources of rain, tap, rice, lake, river, and sea. As seen in Figure S5, SI, in the detecting systems with different water samples, TZPzine- 1 could successfully monitor the concentra- 
tion of hydrazine with no obvious interference. This result was beneficial for the concept of close-loop detection of the nitrogen cycle.

\subsection{Cell Imaging}

As an anti-cancer candidate, TZPzine- 1 itself showed anti-proliferation activity. Fortunately, the detecting period was in $20 \mathrm{~min}$ and TZPzine- 1 could easily be degraded in vivo, thus guaranteeing the safety of the detecting system. Afterwards, we conducted biological imaging with TZPzine-1 in living HeLa cells (Figure 6). After being co-cultured with TZPzine-1 only for $30 \mathrm{~min}$, the cells indicated no obvious intracellular fluorescence, which ensured the low background noise, as shown in Figure $6 \mathrm{a}-\mathrm{c}$. When the cells were treated with TZPzine- 1 for $30 \mathrm{~min}$ and then incubated with hydrazine of $100 \mu \mathrm{M}$ (Figure $6 \mathrm{~d}-\mathrm{f}$ ) and $300 \mu \mathrm{M}$ (Figure $6 \mathrm{~g}-\mathrm{i}$ ) for $20 \mathrm{~min}$, respectively, the enhancement of the fluorescence signal in the blue channel could be observed. Remarkably, a higher concentration of hydrazine caused larger fluorescence enhancement (Figure 6j). Consequently, the results inferred the applicative potential of TZPzine-1 in cellular imaging. Therefore, we could generate the connection of environmental toxicology by checking the data in water and cellular samples.

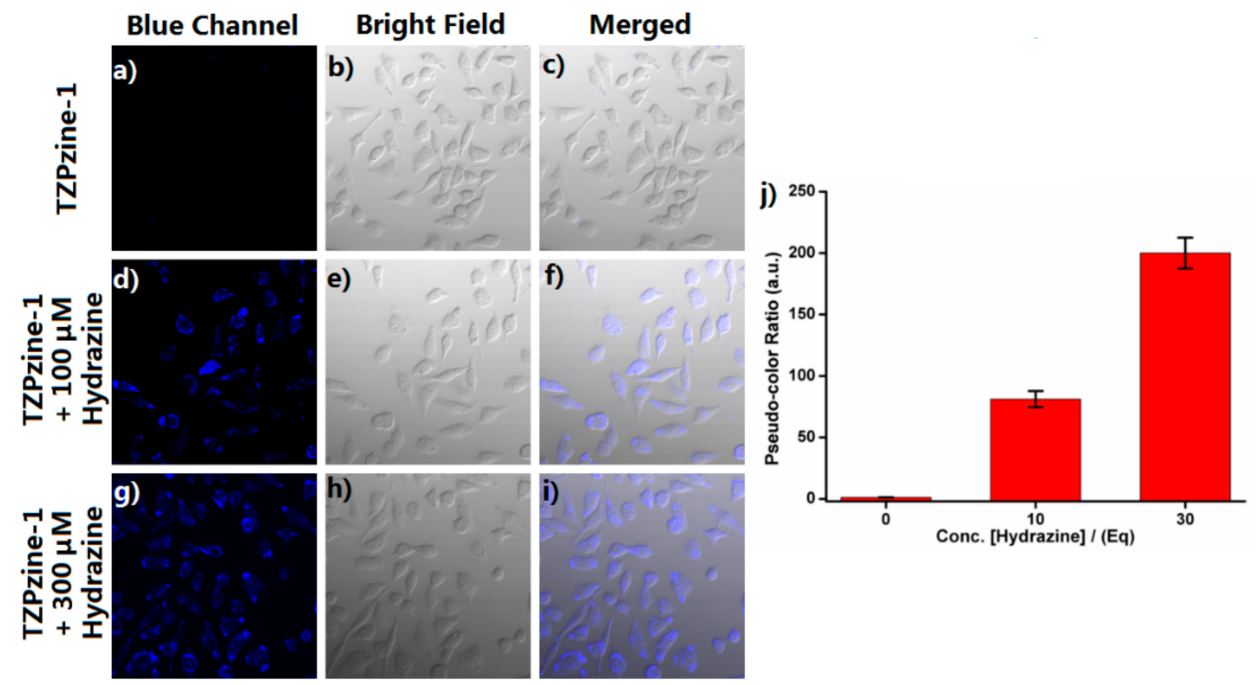

Figure 6. The confocol images of living HeLa cells. Further incubations for 20 min with (a-c) PBS, (d-f) $100 \mu \mathrm{M}$ hydrazine, and (g-i) $300 \mu \mathrm{M}$ hydrazine were conducted, respectively, after a preincubation with $10 \mu \mathrm{M}$ TZPzine- 1 for $30 \mathrm{~min}$. $\lambda_{\mathrm{ex}}=365 \mathrm{~nm}$, blue channel: $400-490 \mathrm{~nm}$. (j) The pseudocolor ratio calculated from three random patches in blue channel pictures of each concentration.

\section{Conclusions}

In summation, we built a novel fluorescent probe with first-time-selected thiazepine backbone, TZPzine-1, for the detection of hydrazine in water samples and living cells. It was picked up in our recent investigation of anti-cancer agents. TZPzine-1 inferred potential advantages including the optical adjustability and the hydrazine-trapping approach. Compared with the typical probes for hydrazine in previous reports (Table S1, SI), TZPzine-1 indicated the necessary advantages including high sensitivity (LOD $=50 \mathrm{nM}$ ), wide linear range ( $0-15$ equiv.), high selectivity (especially from competing species), rapid response (within $20 \mathrm{~min}$ ), and practical steadiness in various $\mathrm{pH}(6.0-11.0)$ and temperature $\left(15-50^{\circ} \mathrm{C}\right)$ conditions. Whilst fulfilling the EPA standard, we successfully applied TZPzine- 1 in the detection of hydrazine in water samples and living cells. This kind of interdisciplinary detection might satisfy the requirements in environmental toxicology, which also agrees with the concept of monitoring the nitrogen cycle. We hope that the information in this work may be favorable for systematic management in future investigations.

Supplementary Materials: The supporting information is available online at https://www.mdpi. com/article/10.3390/bios11050130/s1. Figure S1: The fluorescence intensity at $460 \mathrm{~nm}$ changes 
in various $\mathrm{pH}$ environments, Figure S2: The fluorescence intensity at $460 \mathrm{~nm}$ changes in various temperature conditions, Figure S3: The fluorescence intensity at $460 \mathrm{~nm}$ changes in various time conditions, Figure S4: Job's plots analysis for TZPzine-1 and hydrazine interaction, Figure S5: The application of TZPzine-1 in detecting systems with different water samples from rain, tap, rice, lake, river and sea, Figures S6-S9: NMR and HRMS spectra, Table S1: The comparison with typical probes for hydrazine.

Author Contributions: Conceptualization, Y.-S.Y.; Resources, R.-J.M. and Y.-S.Y.; Investigation, R.-J.M. and M.-K.W.; Methodology, R.-J.M., M.-K.W. and B.Y.; Formal Analysis, M.-K.W.; WritingOriginal Draft, Y.-S.Y.; Writing-Review \& Editing, B.Y. All authors have read and agreed to the published version of the manuscript.

Funding: This work is supported by Guangxi Science and Technology Base and talent Special project (No. Gui Ke AD20159070), Guangxi Natural Science Foundation under Grant (No. 2020GXNSFBA238021; No.2019AC20294), Guangxi University for Nationalities Research Funded Project (No. 2018KJQD13), Nantong University Scientific Research Foundation for the Introduced Talents (No.03081220), and Large Instruments Open Foundation of Nantong University (No. KBJN2024).

Institutional Review Board Statement: Not applicable.

Informed Consent Statement: Not applicable.

Conflicts of Interest: The authors declare no conflict of interest.

\section{References}

1. Canfield, D.E.; Glazer, A.N.; Falkowski, P.G. The evolution and future of Earth's nitrogen cycle. Science 2010, 330, 192-196. [CrossRef] [PubMed]

2. Engelhardt, U. Nonalternating inorganic heterocycles containing hydrazine as building block. Coord. Chem. Rev. 2002, $235,53-91$. [CrossRef]

3. Zhang, X.Y.; Yang, Y.S.; Wang, W.; Jiao, Q.C.; Zhu, H.L. Fluorescent sensors for the detection of hydrazine in environmental and biological systems: Recent advances and future prospects. Coord. Chem. Rev. 2020, 417, 213367. [CrossRef]

4. Gan, L.; Li, B.; Chen, Y.; Yu, B.; Chen, Z. Green synthesis of reduced graphene oxide using bagasse and its application in dye removal: A waste-to-resource supply chain. Chemosphere 2019, 219, 148-154. [CrossRef] [PubMed]

5. Tafazoli, S.; Mashregi, M.; O’Brien, P.J. Role of hydrazine in isoniazid-induced hepatotoxicity in a hepatocyte inflammation model. Toxicol. Appl. Pharm. 2008, 229, 94-101. [CrossRef]

6. Zelnick, S.; Mattie, D.; Stepaniak, P. Occupational exposure to hydrazines: Treatment of acute central nervous system toxicity. Aviat. Space Environ. Med. 2003, 74, 1285-1291.

7. Daemi, S.; Ashkarran, A.A.; Bahari, A.; Ghasemi, S. Fabrication of a gold nanocage/graphene nanoscale platform forelectrocatalytic detection of hydrazine. Sens. Actuat. B Chem. 2017, 245, 55-65. [CrossRef]

8. Gu, X.; Camden, J.P. Surface-enhanced Raman spectroscopy-based approach for ultrasensitive and selective detection of hydrazine. Anal. Chem. 2015, 87, 6460-6464. [CrossRef]

9. Arulraj, A.D.; Vijayan, M.; Vasantha, V.S. Spectrophotometric determination of pico-molar level of hydrazine by using Alizarin red in water and urine samples. Spectrochim. Acta A 2015, 148, 355-361. [CrossRef] [PubMed]

10. Safavi, A.; Baezzat, M. Flow injection chemiluminescence determination of hydrazine. Anal. Chim. Acta 1998, 358, 121-125. [CrossRef]

11. Collins, G.; Rose-Pehrsson, S. Fluorescent detection of hydrazine, monomethylhydrazine, and 1,1-dimethylhydrazine by derivatization with aromatic dicarbaldehydes. Analyst 1994, 119, 1907-1913. [CrossRef]

12. Malone, H. Determination of mixtures of hydrazine and 1,1-dimethylhydrazine. Anal. Chem. 1961, 33, 575-577. [CrossRef]

13. Qian, Y.; Lin, J.; Han, L.J.; Lin, L.; Zhu, H.L. A resorufin-based colorimetric and fluorescent probe for live-cell monitoring of hydrazine. Biosens. Bioelectron. 2014, 58, 282-286. [CrossRef]

14. Goswami, S.; Das, S.; Aich, K.; Pakhira, B.; Panja, S.; Mukherjee, S.K.; Sarkart, S. A chemodosimeter for the ratiometric detection of hydrazine based on return of ESIPT and its application in live-cell imaging. Org. Lett. 2013, 15, 5412-5415. [CrossRef] [PubMed]

15. Lee, M.H.; Yoon, B.; Kim, J.S.; Sessler, J.L. Naphthalimide trifluoroacetyl acetonate: A hydrazine-selective chemodosimetric sensor. Chem. Sci. 2013, 4, 4121-4126. [CrossRef]

16. Li, J.; Cui, Y.C.; Bi, C.X.; Feng, S.Q.; Yu, F.Z.; Yuan, E.; Xu, S.Z.; Hu, Z.; Sun, Q.; Wei, D.G.; et al. Oligo (ethylene glycol)functionalized ratiometric fluorescent probe for the detection of hydrazine in vitro and in vivo. Anal. Chem. 2019, 91, 7360-7365. [CrossRef] [PubMed]

17. Dai, X.; Wang, Z.Y.; Du, Z.F.; Miao, J.Y.; Zhao, B.X. A simple but effective near-infrared ratiometric fluorescent probe for hydrazine and its application in bioimaging. Sens. Actuat. B Chem. 2016, 232, 369-374. [CrossRef]

18. Sun, M.D.; Guo, J.; Yang, Q.B.; Xiao, N.; Li, Y.X. A new fluorescent and colorimetric sensor for hydrazine and its application in biological systems. J. Mater. Chem. B 2014, 2, 1846-1851. [CrossRef] 
19. Wang, W.D.; Hu, Y.; Li, Q.; Hu, S.L. A carbazole-based turn-on fluorescent probe for the detection of hydrazine in aqueous solution. Inorg. Chim. Acta 2018, 477, 206-211. [CrossRef]

20. Lu, Z.L.; Fan, W.L.; Shi, X.M.; Lu, Y.A.; Fan, C.H. Two distinctly separated emission colorimetric NIR fluorescent probe for fast hydrazine detection in living cells and mice upon independent excitations. Anal. Chem. 2017, 89, 9918-9925. [CrossRef] [PubMed]

21. Shi, X.R.; Huo, F.J.; Chao, J.B.; Yin, C.X. A ratiometric fluorescent probe for hydrazine based on novel cyclization mechanism and its application in living cells. Sens. Actuat. B Chem. 2018, 260, 609-616. [CrossRef]

22. Choi, M.G.; Hwang, J.; Moon, J.O.; Sung, J.; Chang, S.K. Hydrazine-selective chromogenic and fluorogenic probe based on levulinated coumarin. Org. Lett. 2011, 13, 5260-5263. [CrossRef] [PubMed]

23. Wu, Q.Q.; Zheng, J.L.; Zhang, W.C.; Wang, J.B.; Liang, W.L.; Stadler, F.J. A new quinoline-derived highly-sensitive fluorescent probe for the detection of hydrazine with excellent large-emission-shift ratiometric response. Talanta 2019, 195, 857-864. [CrossRef]

24. Ali, F.; Anila, H.A.; Taye, N.; Mogare, D.G.; Chattopadhyay, S.; Das, A. Specific receptor for hydrazine: Mapping the in situ release of hydrazine in live cells and in an in vitro enzymatic assay. Chem. Commun. 2016, 52, 6166-6169. [CrossRef] [PubMed]

25. Jung, Y.; Ju, I.G.; Choe, Y.H.; Kim, Y.; Park, S.; Hyun, Y.M.; Oh, M.S.; Kim, D. Hydrazine expos: The next-generation fluorescent probe. ACS Sens. 2019, 4, 441-449. [CrossRef] [PubMed]

26. Wu, J.J.; Pan, J.; Ye, Z.; Zeng, L.T.; Su, D.D. A smart fluorescent probe for discriminative detection of hydrazine and bisulfite from different emission channels. Sens. Actuat. B Chem. 2018, 274, 274-284. [CrossRef]

27. Qi, Y.L.; Chen, J.; Zhang, B.; Li, H.; Li, D.D.; Wang, B.Z.; Yang, Y.S.; Zhu, H.L. A turn-on fluorescent sensor for selective detection of hydrazine and its application in Arabidopsis thaliana. Spectrochim. Acta A 2020, 227. [CrossRef] [PubMed]

28. Li, X.Y.; Yu, Z.Y.; Li, N.; Jia, H.S.; Wei, H.; Wang, J.; Song, Y.T. Design and synthesis of dual-excitation fluorescent probe, $\mathrm{Tb}^{3+}$-dtpa-bis(fluorescein), and application in detection of hydrazine in environmental water samples and live cells. Dyes Pigment. 2019, 162, 281-294. [CrossRef]

29. Meher, N.; Panda, S.; Kumar, S.; Lyer, P.K. Aldehyde group driven aggregation-induced enhanced emission in naphthalimides and its application for ultradetection of hydrazine on multiple platforms. Chem. Sci. 2018, 9, 3978-3985. [CrossRef]

30. Zhao, Z.L.; Zhang, G.; Gao, Y.; Yang, X.Y.; Li, Y.H. A novel detection technique of hydrazine hydrate: Modality change of hydrogen bonding-induced rapid and ultrasensitive colorimetric assay. Chem. Commun. 2011, 47, 12816-12818. [CrossRef] [PubMed]

31. Chen, W.; Wang, H.; Tang, H.R.; Yang, C.; Guan, X.P.; Li, Y.X. Amperometric sensing of hydrazine by using single gold nanopore electrodes filled with Prussian Blue and coated with polypyrrole and carbon dots. Microchim. Acta 2019, 186, e350. [CrossRef]

32. Wang, B.; Wang, L.R.; Liu, L.L.; Wang, W.; Man, R.J.; Zheng, D.J.; Deng, Y.S.; Yang, Y.S.; Xu, C.; Zhu, H.L. A novel series of benzothiazepine derivatives as tubulin polymerization inhibitors with anti-tumor potency. Bioorg. Chem. 2021, 108, 104585. [CrossRef] [PubMed]

33. LeBlanc, R.; Dickson, J.; Brown, T.; Stewart, M.; Pati, H.N.; VanDerveer, D.; Arman, H.; Harris, J.; Pennington, W.; Holt, H.L., Jr.; et al. Synthesis and cytotoxicity of epoxide and pyrazole analogs of the combretastatins. Bioorg. Med. Chem. 2005, 13, 6025-6034. [CrossRef]

34. Ducki, S. Antimitotic chalcones and related compounds as inhibitors of tubulin assembly. Anticancer Agents Med. Chem. 2009, 9, 336-347. [CrossRef] [PubMed]

35. Hartle, M.D.; Sommer, S.K.; Dietrich, S.R.; Pluth, M.D. Chemically reversible reactions of hydrogen sulfide with metal phthalocyanines. Inorg. Chem. 2014, 53, 7800-7802. [CrossRef]

36. Strianese, M.; Lamberti, M.; Pellecchia, C. Chemically reversible binding of $\mathrm{H}_{2} \mathrm{~S}$ to a zinc porphyrin complex: Towards implementation of a reversible sensor via a "coordinative-based approach". Dalton Trans. 2017, 46, 1872-1877. [CrossRef] [PubMed] 